\title{
DFT study of NLO properties of boroxine based octupolar molecules
}

\author{
F. Ibersiene, ${ }^{a, b}$ D. Hammoutène, ${ }^{a}$ A. Boucekkine, ${ }^{b}$ C. Katan, ${ }^{c}$ M. Blanchard-Desce ${ }^{c}$ \\ ${ }^{a}$ Laboratoire de Thermodynamique et Modélisation Moléculaire, U.S.T.H.B, BP 32, El Alia \\ 16111 Bab Ezzouar, Alger, Algeria

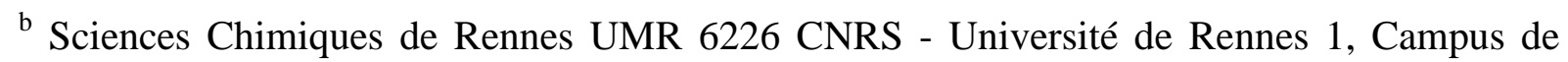 \\ Beaulieu, 35042 Rennes Cedex, France \\ ${ }^{\mathrm{c}}$ Chimie et Photonique Moléculaires UMR 6510 CNRS - Université de Rennes 1, Campus de \\ Beaulieu, 35042 Rennes Cedex, Rennes, France
}

\begin{abstract}
First-order nonlinear optical properties of a series of octupolar boroxine derivatives are investigated using Density Functional Theory (DFT) calculations. Boroxine acting as an electron attracting core, we studied the influence, on the computed static $\beta$ hyperpolarizability and on the transparency in the visible region, of the nature of donor substituting groups linked to this core and the effect of the conjugated bridge's length. The variation of this property has also been correlated to HOMO-LUMO gap and to the nature of HOMO and LUMO. The study suggests that some of the boroxine derivatives under consideration may have potential applications in the development of nonlinear optical materials.
\end{abstract}

Key words: DFT; Boroxine; Octupole; NLO; transparency.

*corresponding author: tel: + $33(0) 223236269$

fax: + $33(0) 223236840$

e-mail: aboucekk@univ-rennes1.fr 


\section{1- Introduction}

Nonlinear optical (NLO) phenomena have been extensively studied over the last decades; molecules exhibiting large hyperpolarizabilities have a strong NLO potential and could be used, under conditions, for optoelectronics and a variety of optical devices ${ }^{1-5}$.

Two kinds of systems bearing a significant NLO activity have been considered up to now: traditional charge transfer dipolar molecules ${ }^{6-9}$ or octupolar ${ }^{7,10-13}$ ones. At the molecular level, the first order NLO properties (frequency doubling, Kerr effect, Electro Optical Pockels effect ...) are driven by $\beta$ the first hyperpolarizability. Unfortunately most of molecules of the first kind, i.e. dipolar species, crystallize in centrosymmetric space groups, where the $\chi^{(2)}$ macroscopic susceptibility vanishes ${ }^{9-11}$. In early 1990s, Zyss introduced the concept of octupolar molecule, with 1,3,5-triamino-2,4,6-trinitrobenzene (TATB) $)^{8,12,14}$ as typical example, which is characterized by a non dipolar and non-centrosymmetric planar $\mathrm{C}_{3 \mathrm{~h}}$ or $\mathrm{D}_{3 \mathrm{~h}}$ molecular symmetry. Since then, increasing research attention has been focused on NLO active octupolar molecules, including the extension from planar two dimensional systems, like trisubstituted benzenes (triphenylbenzenes) $)^{15}$, hexasubstituted benzenes ( tricyanobenzenes, trinitrobenzenes, trimethoxybenzenes and phenylacetylene mesitylenes) ${ }^{16-}$ 17, 1,3,5-triazines ${ }^{18-22}$, to $\mathrm{D}_{2}, \mathrm{D}_{3}$, or $\mathrm{T}_{\mathrm{d}}$ characterized three-dimensional ones ${ }^{23-24}$. An advantage of octupolar molecules is that they seem likely to crystallize in noncentrosymmetric space groups due to the lack of ground state dipole moment.

The octupolar framework provides an interesting route towards enhanced NLO responses and improved transparency. The first hyperpolarizability is a strong function of the absorption maximum especially in dipolar systems, as it can be seen from the two-level model ${ }^{25}$, so that high $\beta$ s are generally accompanied by absorption at large wavelengths.

Because even a small absorption at the operating wavelengths of electro-optic devices (typically 1.3 or $1.5 \mu \mathrm{m}$ ) can be detrimental, it is important to make NLO chromophores as transparent as possible. Furthermore, for frequency doubling applications one would require materials that are simultaneously transparent at the fundamental and second harmonic wavelength. 
We report in this paper, a DFT computational study of series of octupolar compounds based on the boroxine ring. Indeed, despite boron inorganic crystals such as BBO (beta barium borate, $\beta-\mathrm{BaB}_{2} \mathrm{O}_{4}$ ), which is widely used in wavelength conversion devices, have long been known to display interesting NLO properties, the potentialities of molecular boroxine derivatives for NLO have not been overlooked until recently ${ }^{26}$ in the context of a nonlinearitytransparency trade-off.

In this work, three octupolar series of compounds are investigated; molecules are built from the boroxine ring symmetrically grafted with three electron-releasing groups linked to the boron atoms. By increasing the electron-donating strength of substituting groups, we are aiming to increase their NLO responses. Phenyl units were selected as rigid linkers between donating substituting groups and the boroxine core so as to allow periphery-to-core intramolecular charge-transfer to take place while maintaining suitable transparency. In investigating these new compounds, the challenge is to help to the design of effective materials exhibiting both improved transparency and higher nonlinearity than TATB or the widely studied octupolar triazine derivatives.

\section{2- Computational details}

DFT theory was chosen to compute the first order hyperpolarizabilities of our systems, this choice being dictated by its reliability already discussed ${ }^{27-31}$ as well as the big size of the molecules under consideration which makes impracticable sophisticated post-Hartree-Fock calculations.

For our part we made use of the Gaussian $03^{32}$ package. Practically, after optimizing geometries, the $\beta_{\mathrm{ijk}}$ tensorial components are determined using Finite-Field (FF) Theory ${ }^{33}$ implemented in the same package. So, the third rank tensor of first hyperpolarizability is described by a $3 \times 3 \times 3$ matrix. The matrix is reduced to 10 components due to Kleinman symmetry ${ }^{34}$.

Zyss et al. ${ }^{35}$ have developed and discussed the tensorial nature of the first hyperpolarizability for octupolar molecules.

The relevant expression used for the calculation of the total $\beta$ value is the following ${ }^{36}$ : 
$\beta_{\text {tot }}^{2}=\beta_{\mathrm{xxx}}^{2}+\beta_{\mathrm{yyy}}^{2}+\beta_{\mathrm{zzz}}^{2}+3 \beta_{\mathrm{xyy}}^{2}+3 \beta_{\mathrm{xzz}}^{2}+\beta_{\mathrm{yzz}}^{2}+3 \beta_{\mathrm{yxx}}^{2}+3 \beta_{\mathrm{zxx}}^{2}+3 \beta_{\mathrm{zyy}}^{2}+6 \beta_{\mathrm{xyz}}^{2}$

This formula is also used to compute semi-empirical $\mathrm{AM}^{37} \beta$ values with the MOPAC ${ }^{38}$ program.

It is well documented ${ }^{14,39-41}$ that considering small molecules, computed $\beta$ values are very sensitive to the used basis sets, and that diffuse functions play an important role. Moreover, it is expected that the first hyperpolarizability values should also depend on the used DFT functional $^{29-31}$.

For our part, to assess and check our method of calculation we carried out first the computation of the NLO property under consideration at two levels of DFT, namely the two well known different hybrid functionals, $\mathrm{B} 3 \mathrm{LYP}^{42}$ and $\mathrm{PBE} 0^{43}$ using different standard basis sets, 6-31G*, 6-31+G**, 6-311G**, 6-311+G**. This has been done for several test molecules, like triphenyl boroxine (TPB) and para dimethylamino-TPB (A5).

We found that the relative variation of $\beta$ when changing the basis set or the functional was always less than $10 \%$. It is worth noting that for the rather big systems under consideration the influence of the basis set extension seems to be less crucial than for small molecules. Thus, we retained the standard B3LYP/6-31G* for all our study.

In both Gaussian 03 and MOPAC packages, $\beta_{\mathrm{ijk}}$ are given in atomic units and defined via a Taylor expansion of the dipole moment. Experimental data being given using the $\beta^{\mathrm{X}}$ convention, the relation between the two $\beta \mathrm{s}$ is ${ }^{44}$ :

$$
\beta^{\mathrm{T}}=4 \beta^{\mathrm{X}}
$$

$\beta$ values reported in table 1 are within $\beta^{\mathrm{X}}$ convention, theoretical values are thus divided by 4 to compare them to experimental ones. 


\section{Systems under consideration}

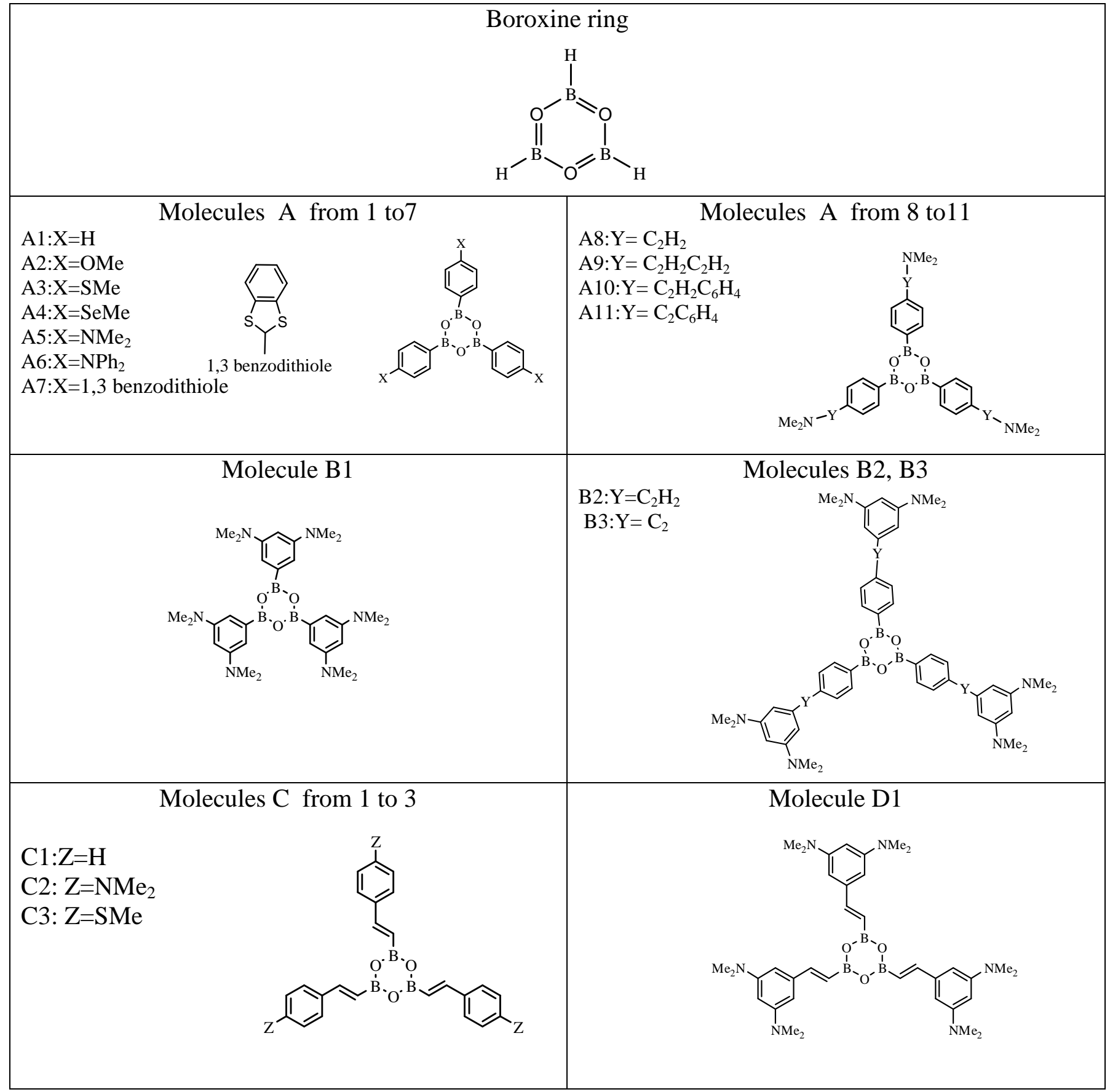

Scheme 1: Boroxine derivatives under study. 
The boroxine core is stable, planar ${ }^{26,45}$ in both DFT optimized and crystallographic structures, electron-deficient, and has a low aromaticity ${ }^{46}$.

The molecules chosen in this study contain a central boroxine ring symmetrically substituted by donor groups bonded to the boron atoms in 1, 3 and 5 positions (Scheme 1).

Phenyl units were selected as rigid linkers (in A and B molecules) between the donor groups and the boroxine core so as to allow periphery-to-core intramolecular charge transfer to take place while maintaining suitable transparency. TPB, triphenyl boroxine is compound A1.

Our compounds are predominantly hypothetic, a planar geometry is assumed for most of them; such planarity is a favourable factor for conjugation and hence for a better NLO response. Almost all these molecules exhibit a $\mathrm{C}_{3 \mathrm{~h}}, \mathrm{D}_{3 \mathrm{~h}}, \mathrm{C}_{3}$ or $\mathrm{D}_{3}$ octupolar symmetry.

Three series are considered for discussion (scheme 1):

In series $\mathrm{A}, \mathrm{A} 2-\mathrm{A} 7$, a standard donating group, i.e. $\mathrm{NMe}_{2}, \mathrm{OMe}, \mathrm{NPh}_{2} \ldots$ or 1-3 benzodithiole ends the TPB skeleton.

For A8-A11, a conjugated bridge $\mathrm{Y}$ is introduced at the phenyl para position between TPB and the donor $\mathrm{X}\left(\mathrm{NMe}_{2}\right)$ group.

In series B, B1-B3, the effect of locating two $\mathrm{NMe}_{2}$ donating groups at positions 3,5 of the ending phenyl rings rather than one $\mathrm{NMe}_{2}$ at para position, is studied.

In series $\mathrm{C}, \mathrm{C} 1-\mathrm{C} 3$, the substituted phenyl groups are not attached directly to the boroxine core but to vinyl moieties themselves linked at positions 1, 3 and 5 of boroxine.

\section{3- Results and discussion}

In table 1 are reported computed and measured properties for the three series of compounds. Hyperpolarizabilities are in $\beta^{\mathrm{X} 44}$ convention.

In columns 3 and 4 , are given the static $\beta_{\text {theo }}$ and dynamical (SHG) $\beta_{\text {theo }}$ AM1 results. 
In columns 5 to 8 , we show the static $\beta_{\text {theo, }}$ the HOMO and HOMO-LUMO gap energies as well as $\lambda_{\text {gap }}$ which is the wavelength corresponding to the HOMO-LUMO gap, computed at the B3LYP/6-31G* level.

Experimental values, i.e. $\lambda_{\exp }$ the maximum absorption wavelength and static $\beta_{\exp }($ at $\omega=0)$ and dynamical $\beta_{\exp }($ at $\omega=1064 \mathrm{~nm})$ hyperpolarizabilities are shown in the last three columns of the table.

Table 1: $\beta$ first hyperpolarizability values $\left(10^{-30} \mathrm{esu}\right)$, HOMO, HOMO-LUMO gap energies $(\mathrm{eV}), \lambda_{\text {gap }}, \lambda_{\exp }(\mathrm{nm})$ wavelengths

\begin{tabular}{|c|c|c|c|c|c|c|c|c|c|c|}
\hline \multicolumn{2}{|l|}{ 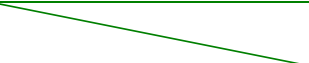 } & \multicolumn{2}{|c|}{ AM1 calculations } & \multicolumn{4}{|c|}{ B3LYP/6-31G* calculations } & \multicolumn{3}{|c|}{ Experimental values } \\
\hline Compd. & Sym. & $\begin{array}{l}\beta_{\text {theo }} \\
(\omega=0)\end{array}$ & $\begin{array}{l}\beta_{\text {theo }} \\
(\omega=1064 \mathrm{~nm})\end{array}$ & $\begin{array}{c}\beta_{\text {theo }} \\
(\omega=0)\end{array}$ & $\begin{array}{l}\text { HOMO } \\
\text { energy }\end{array}$ & $\begin{array}{l}\text { HOMO- } \\
\text { LUMO } \\
\text { gap }\end{array}$ & $\lambda_{\text {gap }}$ & $\lambda_{\text {exp }}$ & $\begin{array}{l}\boldsymbol{\beta}_{\exp } \\
(\omega=0)\end{array}$ & $\begin{array}{l}\beta_{\text {exp }} \\
(\omega=1064 \mathrm{~nm})\end{array}$ \\
\hline boroxine & $\mathrm{D}_{3 \mathrm{~h}}$ & - & - & 0.03 & -9.19 & 8.70 & 143 & & & \\
\hline A1 & $\mathrm{C}_{3 \mathrm{~h}}$ & 2 & 3 & 3 & -6.77 & 5.62 & 221 & & & \\
\hline A2* & $\mathrm{C}_{3 \mathrm{~h}}$ & 5 & 8 & 7 & -5.89 & 5.13 & 243 & 241 & 115 & 152 \\
\hline A3 * & $\mathrm{C}_{3 \mathrm{~h}}$ & 9 & 17 & 12 & -5.72 & 4.62 & 269 & 270 & 101 & 146 \\
\hline A4 & $\mathrm{C}_{3 \mathrm{~h}}$ & 11 & 26 & 13 & -5.54 & 4.42 & 281 & & & \\
\hline A5* & $\mathrm{C}_{3 \mathrm{~h}}$ & 10 & 18 & 13 & -4.91 & 4.62 & 270 & 281 & 181 & 249 \\
\hline A6 & $\mathrm{D}_{3}$ & 17 & 37 & 29 & -4.99 & 4.00 & 311 & & & \\
\hline A7 & $\mathrm{C}_{3}$ & 3 & 6 & 5 & -5.61 & 3.99 & 312 & & & \\
\hline A8 & $\mathrm{C}_{3 \mathrm{~h}}$ & 20 & 47 & 29 & -4.57 & 3.85 & 323 & & & \\
\hline A9 & $\mathrm{C}_{3 \mathrm{~h}}$ & 33 & 107 & 56 & -4.40 & 3.37 & 369 & & & \\
\hline A10 & $\mathrm{C}_{3 \mathrm{~h}}$ & 29 & 84 & 77 & -4.68 & 3.34 & 372 & & & \\
\hline A11 & $\mathrm{D}_{3 \mathrm{~h}}$ & 29 & 73 & 76 & -4.84 & 3.48 & 357 & & & \\
\hline B1 & $\mathrm{D}_{3 \mathrm{~h}}$ & 5 & 9 & 0.5 & -4.46 & 4.06 & 307 & & & \\
\hline B2 & $\mathrm{C}_{3 \mathrm{~h}}$ & 1 & 8 & 31 & -4.68 & 3.27 & 380 & & & \\
\hline B3 & $\mathrm{D}_{3 \mathrm{~h}}$ & 1 & - & 31 & -4.76 & 3.33 & 373 & & & \\
\hline C1 & $\mathrm{C}_{3 \mathrm{~h}}$ & 4 & 6 & 8 & -6.07 & 4.49 & 277 & & & \\
\hline $\mathrm{C2}$ & $\mathrm{C}_{3 \mathrm{~h}}$ & 18 & 41 & 30 & -4.77 & 3.87 & 322 & & & \\
\hline C3 & $\mathrm{C}_{3 \mathrm{~h}}$ & - & - & 25 & -5.49 & 3.98 & 313 & & & \\
\hline D1 & $\mathrm{C}_{3}$ & - & - & 7 & -4.79 & 3.69 & 338 & & & \\
\hline TATB ${ }^{*}$ & $\mathrm{D}_{3 \mathrm{~h}}$ & - & - & 4 & & & & & & \\
\hline TIATB ${ }^{*}$ & & - & - & 6 & & & & & 14 & \\
\hline TPT $^{* * *}$ & & - & - & 4 & & & & & & \\
\hline
\end{tabular}

From ref 26

${ }^{* *}$ From ref 18 ( triphenyl triazine :CPHF/6-31G) 
We discuss first the B3LYP results.

As it can be seen, the boroxine ring and TPB (compound A1) display a rather low $\beta$ value equal to $0.0310^{-30}$ and $310^{-30}$ esu respectively.

Compared to widely studied triazines, TPB show comparable $\beta$ value as TPT (Tri Phenyl Triazine) i.e. $410^{-30} \mathrm{esu}$, noting however that the method of calculation is not the same ${ }^{46}$. As it can be observed, experimental or computed $\beta$ values of a boroxine derivative like A5 $\left(\mathrm{X}=\mathrm{NMe}_{2}\right)$ is higher than TIATB ones (a soluble analogue of TATB).

Substituting a donating group $\mathrm{X}=\mathrm{OMe}, \mathrm{SMe}, \mathrm{NMe}_{2}, \mathrm{NPh}_{2}$, at the phenyl para position of TPB (scheme 1) leading respectively to compounds A2-A3, A5-A6 enhances greatly $\beta$; for instance for $\mathrm{A} 6\left(\mathrm{X}=\mathrm{NPh}_{2}\right) \beta$ is multiplied by nine $\left(2910^{-30} \mathrm{esu}\right)$ relatively to TPB. Note also that a SMe group leads to the same activity as $\mathrm{NMe}_{2}$; indeed, $\mathrm{A} 4$ and $\mathrm{A} 5$ exhibit the same $\beta$ value equal to $1310^{-30} \mathrm{esu}$. It is worth noting that for the latter molecules, the obtained $\beta$ are greater than TATB and TIATB's, the latter molecules being standard 2D octupolar species.

More importantly, the magnitude of $\beta$ is dependent on the bridge's length; a comparison of A5 and $\mathrm{A} 8$, shows that including a double $\mathrm{C}-\mathrm{C}$ bond between TPB and $\mathrm{NMe}_{2}$ increases $\beta$ by a factor 2; for instance $\beta$ equals 12 and $2910^{-30}$ esu for A5 and A8 respectively.

The replacement of a vinyl bridge by a phenyl one enhances $\beta$; for instance $\beta$ equals 56 and $7710^{-30}$ esu for A9 and A10 respectively. On the contrary, no difference is noticed when a C$\mathrm{C}$ double bond is replaced by a triple one, as it can be seen comparing A10 and A11 which bear both a $\beta$ value equal to $76-7710^{-30}$ esu.

It is interesting to note that a correlation exists between HOMO-LUMO gaps and $\beta$ values; lower is the gap, higher is $\beta . \mathrm{A} 7(\mathrm{X}=1-3$ benzodithiole) is an exception with a gap close to that of $\mathrm{A} 6\left(\mathrm{X}=\mathrm{NPh}_{2}\right)$ but with a $\beta$ value completely different.

For A1-A6, we note also that the increase of $\beta$ is related to HOMO's energy; generally, higher is the HOMO, larger is $\beta$. This HOMO (and HOMO-1) is mainly localized on the substituting $\mathrm{X}$ group so that its energy is indicative of the donating character of $\mathrm{X}$ (Scheme 2) and as expected the LUMO (LUMO+1) bears a predominating boroxine character. Strong donating groups lead to high $\beta$ values. 


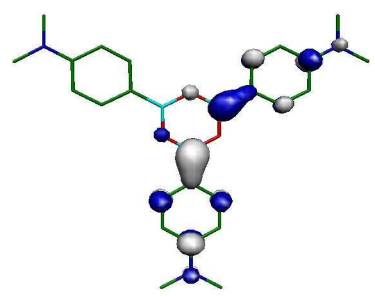

I.IJMO A5

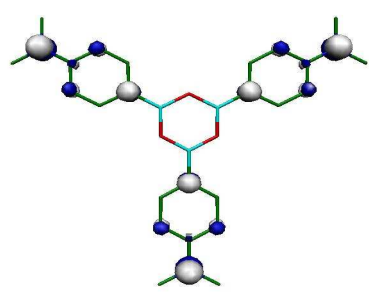

HOMO A5
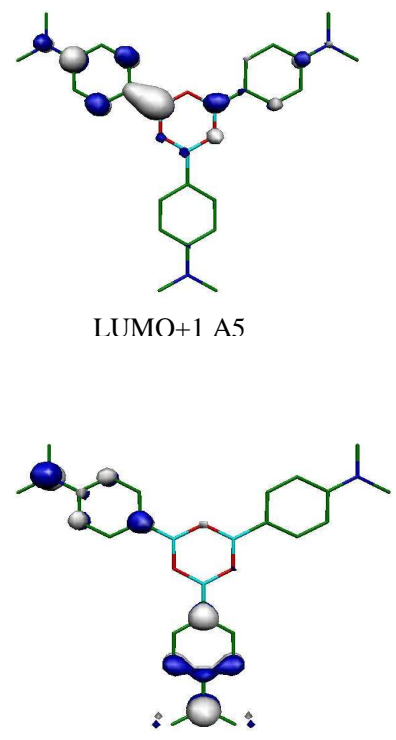

HOMO-1 A5

Scheme 2: Frontier orbitals of A5

In series $\mathrm{B}$, when we graft the $\mathrm{NMe}_{2}$ donor group at meta positions 3 and 5 of TPB, like in $\mathrm{B} 1$, rather than at para position, $\beta$ drops from $1310^{-30}$ esu (A5) to $0.510^{-30} \mathrm{esu}$ (B1), and when including a bridge between TPB and the substituting $\mathrm{NMe}_{2}$ donor group, as in B2- B3, one can see that the $\beta$ values are half of their A10-A11 counterparts. It is thus seen that locating a single $\mathrm{NMe}_{2}$ donating group at the para phenyl position insures the highest $\beta$ values. This result is not surprising the para position of the donating group insuring a better conjugation with the rest of the molecule.

In series $C$, a vinyl group is directly linked to boroxine. No remarkable enhancement of $\beta$ is noticed with such a skeleton. Comparing $\mathrm{C} 2$ and its $\mathrm{A} 8$ congener, shows that their $\beta$ s are equal as well as their HOMO-LUMO gaps.

For compound D1, where bridge's and position's effects are combined, it can be seen that the 3 and 5 meta positions on the phenyl ring remains a negative factor for the quadratic hyperpolarizability. Indeed, despite the presence of two donating groups such as $\mathrm{NMe}_{2}$, and the extension of conjugation, D1 has a $\beta$ of the same order of magnitude as $\mathrm{A} 2(\mathrm{X}=\mathrm{OMe})$, or $\mathrm{C} 1$, which bears no $\mathrm{X}$ donating group.

As in series $\mathrm{A}$, we note that $\mathrm{B}$ and $\mathrm{C}$ series display the same correlation between $\beta$ and HOMO-LUMO gap, but the correlation with HOMO's energies is fulfilled by $\mathrm{C}$ series, not by the $\mathrm{B}$ one, although the number of compounds is small in those series. 
Finally, one can see that experimental $\beta_{\mathrm{SHG}}$ and $\beta(0)$ values are only available for A2, A3 and $\mathrm{A} 5^{26}$. Also, quantitative agreement between computed and experimental values is poor.

We remark also an inversion between experimental and computed values concerning A2 $(\mathrm{X}=\mathrm{OMe})$ an $\mathrm{A} 3(\mathrm{X}=\mathrm{SMe})$. Taking into account Hammett constants, the ranking of the donating strengths is: $\mathrm{SMe}(\mathrm{A} 3)<\mathrm{OMe}(\mathrm{A} 2)<\mathrm{NMe}_{2}$ (A5) which corresponds to the same ranking as $\beta_{\exp }(0)$. On another hand the theoretical ranking is consistent with the donating strength of the groups as measured by the HOMO energy (table 1) showing that SMe is slightly more donating than OMe. These results agree with early investigation on theses compounds $^{26}$. Nevertheless there is not a great difference between the experimental values of A2 and A3. Calculated values reproduce global trends; however quantitative agreement with experimental values is poor $^{26}$. This gives us confidence that our theoretical results are, at least qualitatively, reliable.

We investigate now the transparency of the species under consideration.

A crude estimate of the maximum absorption wavelength can be deduced from the HOMOLUMO energy gap and is reported in table 1 ( $\lambda_{\text {gap }}$ values) although accurate values need the use of Time Dependent DFT (TDDFT). A very good agreement is found between experimental $\lambda_{\exp }$ and $\lambda_{\text {gap }}$ for $\mathrm{A} 2, \mathrm{~A} 3$ and $\mathrm{A} 5^{26}$. Maximum absorption wavelengths experimentally determined equal 241, 270, $281 \mathrm{~nm}$, whereas computed values equal 243, 269, $270 \mathrm{~nm}$ respectively.

First, it is worth noting that all $\lambda_{\text {gap }}$ values are in the UV region.

However, as expected, $\lambda_{\text {gap }}$ values are red shifted with bridge's length, as it can be observed in A series.

In series B, no improvement in transparency is observed; on the contrary, red shift is more pronounced than in A series.

In series $\mathrm{C}, \mathrm{C} 1$ compound displays a bathochromic shift about $56 \mathrm{~nm}$, comparing to A1 one, so that one can expect higher values for $\lambda_{\text {gap }}$ if the conjugated bridge is extended.

Finally, the compounds of series A lead to the best nonlinearity-transparency trade-off.

As it has been said before, semi- empirical calculations at the AM1 level ${ }^{37}$ using the MOPAC package $^{38}$ have also been performed for comparison. Results (table 1 ) show that AM1 $\beta_{\text {theo }}$ values are lower but display the same trend as B3LYP/6-31G* ones. MOPAC permits also the 
computation of dynamical SHG $\beta$ s. As expected, the computed $\beta(0)$ and $\beta(\omega)$ exhibit the same trend, the latter values at $\omega=1064 \mathrm{~nm}$ being higher by a factor 1.5 to 2.5 than the static ones. We notice also, the same inversion of the $\beta$ values between $A 2$ and A3 when comparing to the experimental ones as observed at the DFT level of computation.

\section{4- Conclusions}

DFT calculations at the B3LYP/6-31G* were carried out on three series of octupolar boroxine based compounds. $\beta$ static first-order hyperpolarizabilities have been computed and have been shown to depend on the length of the conjugated bridge linking the boroxine core to the peripheral donating groups, and the nature and the location of the latter group. Most of the studied boroxine based molecules display markedly an improved nonlinearity-transparency trade-off as compared to the prototypical organic octupolar 1, 3, 5-triamino-2, 4, 6trinitrobenzene (TATB) or the widely studied octupolar triazine derivatives.

Considering Tri Phenyl Boroxine (TPB) as a reference skeleton, it is found that a donating group like $\mathrm{NMe}_{2}$ must be placed at the para position of the phenyl ring in order to induce the highest $\beta$ value.

Among all the studied compounds, A10 and A11, the largest molecules, characterized by an extended conjugated bridge, a $\mathrm{NMe}_{2}$ donating group placed at a para position of the phenyl ring linked to the boroxine core, exhibit very large NLO responses, i.e. a $\beta$ value equal to 77 $10^{-30} \mathrm{esu}$. Moreover it appears from the $\lambda_{\text {gap }}$ computed values, that among the most interesting compounds several of them should be transparent in the visible region. Such compounds should be good candidates to experiment.

\section{Aknowledgements:}

We thank the French and Algerian governments for the research grant CMEP/07 MDU 700.

F.I. thanks the Ministère de l'Enseignement Supérieur et de la Recherche Scientifique of Algeria for a fellowship during her research stay at the University of Rennes 1. 


\section{References}

[1] J. Zyss (Ed.), Molecular Nonlinear Optics: Materials, Physics and Devices, Academic Press, Boston, 1993

[2] M. Albota, D. Beljonne, J.L. Brédas, J.E. Ehrlich, J.Y. Fu, A. A. Heikal, S. E. Hess, T. Kogej, M. D. Levin, S. R. Marder, D. McCordmaughon, J. W. Perry, H. Rockel, M. Rumi, C. Subramaniam, W. W. Webb, I. L. Wu and C. Xu, Science, 281 (1998) 1653.

[3] A. M. McDonagh, M. G. Humphrey, M. Samoc and B. Luther-Davies, Organometallics, 18 (1999) 5195.

[4] C. E. Powell, J. P. Morrall, S. A. Ward, M. P. Cifuentes, E. G. A. Notaras, M. Samoc and M. G. Humphrey, J. Am. Chem. Soc., 26 (2004) 12234.

[5] X. Zhou, J. K. Feng and A. M. Ren, Chem. Phys. Lett., 403 (2005) 7.

[6] B. F. Levine and C. G. Bethea, J. Chem. Phys., 63 (1975) 2666.

[7] J. Zyss, Nonlinear Optics, 1 (1991) 3.

[8] a- J.L. Brédas, C. Adant, P. Tackx, A. Persoons and B. M. Pierce, Chem. Rev., 94 ( 1994) 243.

b- G. Park and Ch. Sup. Ra, Bull. Korean Chem. Soc., 24 (2003) 1051.

c- B. A. Sriyanka Mendis and K. M. Nalin de Silva, J. Mol. Struct. (Theochem), 678 (2004) 31 .

[9] J. Zyss, D. S. Chemla and J. F. Nicoud, J. Chem. Phys., 74 (1981) 4800.

[10] M. Joffre, D. Yaron, R.J. Silbey and J. Zyss, J. Chem. Phys., 97 (1 992) 5607.

[11] J. Zyss, S. Brasselet, V. R. Thalladi and G. R. Desiraju, J. Chem. Phys., 109 (1998) 658

[12] J. Zyss and I. Ledoux, Chem. Rev., 94 (1994) 77.

[13] a- B. Illien and A. Botrel, Molecular Engineering, 8 (1998 ) 1.

b- I. Ledoux and J. Zyss, C. R. Physique, 3 (2002) 407.

c- J. L. Braas, F. Meyers, B. M. Pierce, and J. Zyss, J. Am. Chem. Soc., 114 (1992) 4928.

[14] F. Meyers, J. L. Brédas and J. Zyss, J. Am. Chem. Soc., 114 (1992) 2914.

[15] a-J. Brunel, I.Ledoux, J.Zyss and M. Blanchard-Desce, Chem.Commun., 10 (2001) 923.

b- J. Brunel, O. Mongin, A. Jutand, I.Ledoux, J. Zyss and M. Blanchard-Desce, Chem.

Mater., 15 (2003) 4139.

c- J. Brunel, A. Jutand, J. Zyss, and M. Blanchard-Desce, Synthetic Metals, 124 (2001) 195. 
[16] J. J. Wolff, F. Siegler, R. Matschiner and R. Wortmann, Angew. Chem., Int. Ed., 39 (2000) 1436.

[17] a-Y-K. Lee, S-J. Jeon and M. Cho, J. Am . Chem. Soc., 120 (1998) 10921.

b- M. Moreno Oliva, J. Casado, G. Hennrich, J. T. Lopez Navarrete, J. Phys. Chem. B, 110 (2006) 19198

c- M. Moreno Oliva, J. Casado, J. T. Lopez Navarrete, G. Hennrich, M. C. Ruiz

Delgado, J. Orduna, J. Phys. Chem. C, 111 (2007) 18778.

d- M. C. Ruiz Delgado, J. Orduna, M. Moreno Oliva, J. Casado, J. T. Lopez Navarrete, J. Chem. Phys. 127 (2007) 164704.

[18] W. Zhu and Guo-shi Wu, J. Phys. Chem. A, 105 (2001) 9568.

[19] W. Zhu and Guo-Shi Wu, Chem. Phys. Lett., 358 (2002) 1.

[20] V. Thalladi, R. Boese, S. Brasselet, I. Ledoux, J. Zyss, R. K. R. Jetti and G. R. Desiraju , Chem.Commun., 17 (1999) 1639.

[21] S. Brasselet, F. Cherioux, P. Audebert and J. Zyss, Chem. Mater., 11 (1999) 1915.

[22] V. Thalladi, S. Brasselet, H. C. Weiss, D. Bläser, A. K. Katz, H. L. Carrel, R. Boese, J. Zyss, A. Nangia and G. R. Desiraju, J. Am. Chem. Soc., 120 (1998) 2563.

[23] K. Bhanuprakash, and J. L. Rao, Chem. Phys. Lett., 314 (1999) 282.

[24] a-X. Zhou, Ji-K. Feng and Ai-M.Ren, Chem. Phys. Lett., 403 (2005 ) 7.

b- M. Blanchard- Desce, J-B. Baudin, O. Rue1, L. Julien, S. Brasselet and J. Zyss, Optical Materials, 9 (1998) 276.

[25] J.L .Oudar and D.S., Chemla , J. Chem. Phys., 66 (1977) 2664.

[26]a- G. Alcaraz, L.Euzenat, O. Mongin, C. Katan, I. Ledoux, J. Zyss, M. Blanchard-Desce and M. Vaultier, Chem. Commun., 22 (2003) 2766.

b- C. Katan, O. Mongin, G. Alcaraz, M.Vaultier, A. Boucekkine and M. BlanchardDesce, Proc. Spie-Int. Soc. Opt. Eng., 26 (2004) 5517.

[27] S. J. A. van Gisbergen, J. G. Snijders and E. J. Baerends, J. Chem. Phys., 109 (1998) 10657.

[28] a-P. Sałek, O. Vahtras, T. Helgaker and H. Ågren, J. Chem. Phys., 117 (2002) 9630.

b-A. Rizzo, K. Ruud, T. Helgaker, P. Sałek, H. Ågren and O. Vahtras, Chem. Phys. Lett., 372 (2003) 377.

c-P. Sałek, O. Vahtras, J. Guo, Y. Luo, T. Helgaker and H. Ågren, Chem. Phys. Lett., $374(2003) 446$.

d- P. Sałek, T. Helgaker, O. Vahtras, H. Ågren, D. Jonsson and J. Gauss, Mol. Phys., 103 (2005) 439. 
[29] F. A. Bulat, A.Toro-Labbé, B. Champagne, B. Kirtman and W. Yang, J. Chem. Phys., 123 (2005) 014319.

[30] H. Sekino, Y. Maeda, M. Kamiya and K. Hirao, J. Chem. Phys., 126 (2007) 014107.

[31] C.M. Isborn, A. Leclercq, F.D. Vila, L. R. Dalton, J.L. Brédas, B.E. Eichinger and B.H. Robinson, J. Phys. Chem. A, 111 (2007) 1319.

[32] Gaussian 03, D02 version

M. J. Frisch, G. W. Trucks, H. B. Schlegel, G. E. Scuseria, M. A. Robb, J. R. Cheeseman, J. A. Montgomery, Jr., T. Vreven, K. N. Kudin, J. C. Burant, J. M. Millam, S. S. Iyengar, J. Tomasi, V. Barone, B. Mennucci, M. Cossi, G. Scalmani, N. Rega, G. A. Petersson, H. Nakatsuji, M. Hada, M. Ehara, K. Toyota, R. Fukuda, J. Hasegawa, M. Ishida, T. Nakajima, Y. Honda, O. Kitao, H. Nakai, M. Klene, X. Li, J. E. Knox, H. P. Hratchian, J. B. Cross, V. Bakken, C. Adamo, J. Jaramillo, R. Gomperts, R. E. Stratmann, O. Yazyev, A. J. Austin, R. Cammi, C. Pomelli, J. W. Ochterski, P. Y. Ayala, K. Morokuma, G. A. Voth, P. Salvador, J. J. Dannenberg, V. G. Zakrzewski, S. Dapprich, A. D. Daniels, M. C. Strain, O. Farkas, D. K. Malick, A. D. Rabuck, K. Raghavachari, J. B. Foresman, J. V. Ortiz, Q. Cui, A. G. Baboul, S. Clifford, J. Cioslowski, B. B. Stefanov, G. Liu, A. Liashenko, P. Piskorz, I. Komaromi, R. L. Martin, D. J. Fox, T. Keith, M. A. Al-Laham, C. Y. Peng, A. Nanayakkara, M. hallacombe, P. M. W. Gill, B. Johnson, W.

Chen, M. W. Wong, C. Gonzalez, and J. A. Pople

[33] a- H.D.Cohen and C.C.J. Roothaan, J.Chem.Phys., 43 (1965) S34.

b- A. Schweig, Chem. Phys. Lett., 163 (1967) 1.

c- C. H. Meyer and A. Schweig, Theor.Chim.Acta, 29 (1973) 375.

d- J.A. Pople, J.W. McIver Jr and N.S. Ostlund , J. Chem. Phys., 49 (1968) 2960.

[34] D.A . Kleinman, Phys. Rev., 1962 (1977) 126.

[35] J. Zyss, J. Chem. Phys., 98 (1993) 9.

[36] J. L. Rao, PhD thesis, University of Hyderabad, India, 2001

[37] M. J. S. Dewar, E. G. Zoebisch, E. F. Healy and J. J. P. Stewart, J. Am. Chem. Soc., 107 (1985) 3902.

[38] a- J. J. P. Stewart, Int. J. Quant. Chem., 58 (1996) 133.

b- J. J. P. Stewart, Mopac1997 (Tokyo: Fujitsu Ltd).

[39] K. M. Nalin de Silva, J. Mol. Struct. (Theochem), 725 (2005) 243.

[40] G. Uğurlu, E. Kasap , Z. Kantarci and M. Bahat . J. Mol. Struct. (Theochem), 834 (2007) 508.

[41] A. Alparone, A. Millefiori and S. Millefiori , Chem. Phys. Lett., 409 (2005) 288. 
[42] a- A.D. Becke, Phys. Rev. A, 38 (1988) 3098.

b- C. Lee, W. Yang and R. G. Parr, Phys. Rev. B, 37 (1988) 785.

c- P.J. Stephens, F.J. Devlin, C.F. Chabalowski and M.J. Frisch, J. Phys. Chem., 98 (1994) 11623.

[43] a- J. P. Perdew, K. Burke and M. Ernzerhof, Phys. Rev. Lett., 77 (1996) 3865.

b- C. Adamo and V. Barone, J. Chem. Phys., 110 (1999) 6158.

[44] A. Willets, J. E. Rice, D. M. Burland, and D. P. Shelton, J. Chem. Phys., 97 (1992) 7590 .

[45] a- Chin-H.Chang, R.F. Porter and S.H. Bauer, Inorganic Chemistry, 8 (1969) 1689.

b- J.A.Tossell and P. Lazzeretti, J. Phys. Chem., 94 (1990) 1723.

[46] a- J. Beckman, D. Dakternieks, A. Duthie, A. E. K. Lim and E. R.T. Tiekink, J. Organomet. Chem., 633 (2001) 149.

b-P. Lazzeretti and J.A. Tossell, J. Mol. Struct., 82 (1991) 403.

c- D.L. Cooper, S.C. Wright, J. Gerratt and P.A. Hyams, J.Chem. Soc., 6 (1989) 719.

d-R.J. Boyd,S.C. Choi and Ch.C.Hale, Chem. Phys. Lett., 112 (1984) 136. 